\title{
«Я имею вам сказать пару слов». Об идишизмах в Одесских рассказах Исаака Бабеля и польском переводе
}

\author{
Abstract \\ "I Have a Couple of Words I Need to Tell You." Of Yiddishisms in Isaac Babel's The Odessa \\ Stories and Polish Translation
}

The purpose of the article was to analyze Yiddishisms in the cycle of The Odessa Stories (The King, How things were done in Odessa, The father, Lyubka the Cossack) by Isaac Babel and to investigate the adequacy of their Polish translation by Jerzy Pomianowski in relation to the culture of their admission. Upon the material of selected fragments of stories in the original language, the deviations from the norm in the field of syntax and inflection in relation to the literary Russian language appear in the language of their Jewish characters. These fragments were listed in sequence with the proposed variant in Yiddish, which allowed to show that the deviations from the linguistic norm in the Russian variant are the result of Yiddish interference. It was also shown that the Polish variant is adequate to the host culture in terms of language errors, but these errors, unlike the original, do not evoke a connotation with the Jewish cultural circle. These connotations occur in the Polish translation mainly through the preservation of words that call Jewish designations related to Judaism (e.g. Torah, synagogue).

Keywords: The Odessa Stories, Isaac Babel, Yiddishisms, Polish translation, adequacy.

Ключевые слова: Одесские рассказы, Исаак Бабель, идишизмы, польский перевод, адекватность

Язык Одесских рассказов Исаака Бабеля (1894-1940) - явление интересное и наряду с этим спорное. Литературовед Наум Лейдерман, например, отмечает, что Одесские рассказы «воспринимаются как экзотические зарисовки быта одесских евреев, развлекающие читателей пряным арома- 
том одесского жаргона» ${ }^{2}$ В свою очередь, Валерий Смирнов, признанный знаток одесского языка, в книге Крошка Чахес Бабель обстоятельно и не без едкости доказывает, что можно «перечислить по пальцам употребленные в тех рассказах одессизмы» ${ }^{2}$, а действительно наличествующие в них пресловутые «неправильности» являются на самом деле украинизмами, которые «воспринимают не знающие украинского языка читатели за образчики одесской речи» ${ }^{3}$ В В исследовательской литературе по Бабелю, заметим, именно одесский жаргон упоминается как своего рода феномен, определяющий языковую самобытность писателя ${ }^{4}$. Однако, стоило бы, по нашему мнению, задуматься, не слишком ли категорически эти утверждения? Во первых, потому, что четкое определение, чем, по сути, является одеский жаргон пока не существует ${ }^{5}$, а во-вторых, потому, что Одесские рассказы - это отнюдь не документация реального языка Одессы тех времен, а художественное произведение. Поэтому в формулировке «одесский жаргон» бабелевских героев предлагаем перенести ударение со слова «одесский» на слово «жаргон», или, вернее сказать, «язык». Учитывая тот факт, что герои Одесских рассказов - представители еврейского населения, мы присоединяемся к мнению лингвиста Анны Вершик, отмечающей, что язык населенцев Одессы - это, на самом деле, вариант русского языка евреев, стержневым субстратом которого является

1 Русская литература ХХ века (1917-1920-е годы), т. 1, ред. Н.Л. Лейдерман, Москва 2012, с. 407.

2 В. Смирнов, Крошка Чахес Бабель, Одесса 2010, с. 108.

Ibid., c. 109.

4 См. напр.: «Бабель мастерски владел своеобразным одесским жаргоном и сделал его всероссийской ценностью», [в:] П.В. Кузьменко, Самыле скандальнье треугольники русской истории, Москва-Владимир 2012, с. 148; «[...] Исаак Бабель писал по-одесски, писал про одесситов, писал для одесситов», [в:] М. Вайнштейн, Наш Исаак Бабель; того же, А листья снова зеленеют: страницы еврейской русскоязычной литературы, Иерусалим 1988, с. 26; «Бабель писал по-одесски, да к тому же отчаянно утрируя одесскую речь и намеренно заостряя мотивы переплетения культур и национальных пластов», [в:] Р. Огинский, Свобода смеяться [в:] Юмор начала ХХ века: Сборник, Москва 2003, с. 8; «В [...] рассказе, Беня Крик, об одесском гангстере, автор умело использует смешной одесский еврейский жаргон», [в:] Р. Плетнев, История русской литературы ХХ века, Энглвуд 1987, с. 154; «Передать колорит этого собственноручно сделанного одесского слова было одной из задач автора Одесских рассказов. Одесский жаргон, подслушанный писателем с детства, в родном городе, воссоздается, не без поддержки традиции Шолом-Алейхема, в рассказах Бабеля не столько лексикой, сколько главным образом синтаксическими оборотами и специфической интонацией», История русской советской литературы в 4-х томах, т. 1 (1917-1929), ред. А.Г. Дементьев, Москва 1967, с. 362.

5 Одесский жаргон - одно из условных названий одесского языка, «так как не существует однозначного мнения о том, является ли одесский язык самостоятельным языком, диалектом или вариантом русского языка, пиджином или чем-то еще». Подробнее см.: I. Kabanen, Johdatus Odessan. Kielen Erikoispiirteisiin (Введение в особенности одесского языка), Masters Dissertation, University of Helsinki 2008, https://docplayer.ru/27486272-Johdatus-odessan-kielnen-erikoispiirteisiin-vvedenie-v-osobennosti-odesskogo-jazyka.html (доступ: 25.12.2018). Одесский язык - «одесский говор, одесский сленг, одесский жаргон, одесский языковой колорит, типично одесские выражения, русская речь одесситов, одесские словечки, одесско-блатной жаргон, одесское городское койне, характерные одесские фразы, одесское наречие, одесский диалект, В. Смирнов, Одесский язык, Одесса 2008, с. 4. 
идиш. Или, другими словами, язык евреев-ашкеназов ${ }^{6}$. Идиш, как известно, сформировался на базе средневерхнемецких диалектов и заимствований из иврита и славянских языков 7 . Элиаху Фалькович, специалист по идишу, перечислает три основных диалекта данного языка - «украинский, литовско-белорусский и польский», подчеркивая, что «названия эти весьма условны, т.к. границы диалектов не совпадают с границами соответствующих территорий. В каждом диалекте представлено несколько говоров» ${ }^{8}$. Принимая во внимание, что Бабель воспитывался в Одессе ${ }^{9}$, городе по составу поселенцев эклектичном ${ }^{10}$, в котором сосуществовали в едином коммуникативном пространстве русский и идиш в диалектных формах (отсюда и украинизмы, о которых пишет Смирнов), а также то, что писатель наравне с русским владел еврейским языком ${ }^{11}$, вполне вероятно, что все это наложило свой отпечаток на язык героев Одесских рассказов. Можно сказать, и это будет адекватно сути дела, что молдаванские герои-евреи - Бенцион Крик, Сендер Эйхбаум, Любка Швейвейс, Иосиф Мугинштейн и другие говоря на русском языке нередко следуют системе и нормам идиша ${ }^{12}$.

Насколько слова, определяющие реалии иудейской действительности в Одесских рассказах («раввин», «Тора», «синагогальные шамесы», «ермолка», «цадик», «кошерная птица», и др.) имеют свои лексические эквиваленты в принимающем текст языковом пространстве («rabin», «Tora», «bożniczni szamesi», «jarmułka», «cadyk», «koszerny drób»), представляя собой loci communes культуры иудаизма и, следовательно, вызовом для переводчика не являются, настолько передача речи героев-евреев одесского цикла, которые, словами литературоведа Якова Либермана, говорят «по-русски, думая на идише» ${ }^{13}$ может оказаться головоломной

6 А. Вершик, О русском языке евреев, «Die Weltder Slaven» 2003, vol. XLVIII, c. 135-148.

7 Я.Л. Либерман, Исаак Бабель глазами еврея, Екатеринбург 1996, с. 8.

8 Э.М. Фалькович, О языке идиш [в:] Русско-еврейский (идиш) словарь, ред. М.А. Шапиро, И.Г. Спивак, М.Я. Шульман, Москва 1984, с. 714.

9 «Родился в 1894 году в Одессе, на Молдаванке, сын торговца-еврея. По настоянию отца изучал до шестнадцати лет еврейский язык, Библию, Талмуд», [в:] И. Бабель, Автобиография того же Избранное, Москва 1966, с. 23.

10 На становление одесского языка, по мнению Евгения Степанова, лингвиста, автора монографии Російське мовлення Одеси, повлияли языки 12-ти этнических групп, таких как украинцы, россияне, белорусы, молдаване, греки, поляки, евреи, французы, итальянцы, болгары, немцы, армяне. См.: Є.М. Степанов, Російське мовлення Одеси: монографія, Одесса 2004, c. 15-74. Такое богатство речевой палитры вполне объяснимо, учитывая, что Одесса уже начиная с самого ее основания Екатериной II в 1794 году была городом редкостно мультинациональным.

11 «Язык идиш звучал в городе на каждом шагу, и Бабель им владел хорошо. Об этом и свидетельствуют и воспоминания о нем, и его переводы произведений еврейских писателей [...]», [в:] Я.Л. Либерман, ор. cit., с. 12; «Он [Бабель - А.Сь.] превосходно знал быт дореволюционной Одессы и тут русско-еврейский жаргон, на котором объяснялись обитатели Молдаванки», в: Ф. Левин, И. Бабель. Очерк творчества, Москва 1972, с. 10.

12 В Одесских рассказах выступают и заимствования из славянских языков, прежде всего из украинского. Достаточно обратить внимание хотя бы на лексику, например: «хвороба»,«вечерять», «тикать», «галота», «циця», «смачно», «ратуйте». Данный вопрос выходит, однако, за рамки настоящей статьи, поэтому оставим его в стороне.

13 Я.Л. Либерман, op. cit., с. 28. 
задачей. Речь бабелевских «аристократов Молдаванки» по отношению к нормативному русскому языку обнаруживает различия прежде всего на флексийном и синтаксическом уровнях. Причем различия не случайные, а объясняющиеся интерференцией из языка идиш, которые - учитывая целостное восприятие Одесских рассказов - образуют своеобразную «систему» речи характерную исключительно для «молдаванского рыцарства». Можно предположить, что реципиент оригинала - в зависимости от своих знаний воспринимает данные различия либо как просто «коверканье» русского языка, либо как именно последствие влияния идиша. К тому же заметим, что восприятие текста получателем оригинала отличается от восприятия текста получателем перевода. Реципиент перевода ведь не обязан владеть русским языком, а даже если им владеет, не обязан сравнивать исходный текст с производным. Поэтому если учитывать, что перевод для его получателя - произведение существующее в польском культурном пространстве само по себе, а значит, независимо от оригинала, то, следовательно, и оценка качества перевода должна производиться не по отношению к тексту оригинала, а скорее по отношению к принимающему данный текст культурному пространству. Или, другими словами, полагается исследовать не эквивалентность ${ }^{14}$ текста перевода в сопоставлении с текстом оригинала, а его адекватность ${ }^{15}$ культуре, в которой он существует ${ }^{16}$.

В настоящей статье мы постараемся выявить присутствие идишизмов в Одесских рассказах Бабеля, проанализировать их значимость в исходном тексте, а такжерассмотретьадекватностьпольского перевода впринимающей его культуре. В качестве материала для анализа нами выбраны четыре произведения ${ }^{17}$ из цикла Одесские рассказы Бабеля, а именно Корол (1921), Как это делалось в Одессе (1923), Отеи (1934), Любка Казак (1924) и их перевод на польский язык под названием Opowiadania odeskie [1973] (Król, Tak to robiono w Odessie, Ojciec, Lubka Kozak), осуществленным Ежи Помяновским (1921-2016), переводчиком русской литературы, включившим творчество автора Одесских рассказов в польское читательское сознание.

Теперь, имея в виду все сказанное выше, мы можем перейти к непосредственному рассмотрению идишизмов. Итак, анализ начнем с фрагмента, в котором обратим внимание на фразу, вынесенную в заголовок настоящей статьи: «- Слушайте, Корол, - сказал молодой человек, - я имею вам ска-

14 Эквивалентность перевода - общность содержания (смысловая близость) оригинала и перевода, в: В.Н. Комиссаров, Современное переводоведение, Москва 2002, с. 415.

15 Адекватный перевод - перевод, обеспечивающий прагматические задачи переводческого акта на максимально возможном для достижения этой цели уровне эквивалентности, не допуская нарушения норм и узуса ПЯ, соблюдая жанрово стилистические требования к текстам данного типа и соответствия конвенциональной норме перевода. В нестрогом употреблении адекватный перевод - это «правильный перевод», в: ibid., с. 407.

16 Подробнее о восприятии перевода реципиентом см.: R. Lewicki, Obcość w odbiorze przektadu, Lublin 2000, с. 19-39.

17 Данные четыре произведения, изданные при жизни писателя, считаются каноничными. 
зать пару слов. Меня послала тетя Хана с Костецкой...» $(K, \text { с. } 13)^{18}$. Нас здесь особо будет интересовать чуждое русскому языку, но характерное для русского языка евреев присутствие глагола «иметь» в модальной конструкции, выражающей обязанность, желание, возможность и т.д. сделать что-либо: «я имею вам сказать пару слов» ${ }^{19}$. Для сравнения можно привлечь, например: «я хочу вам сказать несколько слов» / «я должен вам сказать несколько слов». В строении анализируемой фразы на русском языке наблюдается ее соответствие идишской структуре предложения, которое может выглядеть следующим образом: Ikh hob a por verter aykh tsu zogn ${ }^{20}$. В идише zogn означает инфинитив («сказать») или, как в данном случае, созданное от него отглагольное существительное, сочетающееся с предлогом $t s u$, т.е. «до». В русском языке «сказать» - это инфинитив, от которого отглагольное существительное не образуется. Интерференция здесь осознается, может быть, не столь отчетливо, поскольку хотя «я имею» полностью совпадает с $I k h$ $h o b$, то «сказать» выступает без предлога, т.е. калькирует zogn в значении не отглагольного существительного, а инфинитива. Для сравнения приведем интересующий нас фрагмент в переводе Помяновского: «- Słuchajcie no, Król - powiedział młody człowiek - mam wam parę słów do powiedzenia. Przychodzę od cioci Chany z Kosteckiej...» (K, c. 293) ${ }^{21 .}$ Польский вариант, как видим, отражает норму идиша: за предлогом «dо» следует отглагольное существительное «powiedzenie» (от глагола «powiedzieć») в косвенном падеже. Такая конструкция в польском языке является вполне корректной, изза чего реципиент перевода по-другому воспринимает текст, чем реципиент оригинала.

Перейдем к следующему примеру: «У вас невыносимый грязь, папаша, - сказала она и выбросила за окно прокисшие овчины, валявшиеся на полу, - но я выведу этот грязь! [...]» (O, с. 27). Здесь мы видим нарушение согласования по роду между существительным («грязь») и прилагательным («невыносимый»), а также местоимением («этот»). В русском языке грязь - существительное женского рода, поэтому как определяющее его прилагательное, так и местоимение должны стоять в том же роде. Род существительных в идише - дело намного сложнее. Существует несколь-

18 Здесь и далее произведения цитируются по изданию И. Бабель, Малое собрание сочинений, Санкт-Петербург 2014. Страницы указываются в тексте статьи в круглых скобках с пометкой К (Корол), КО (Как это делалось в Одессе), O (Отеи), ЛК (Любка Козак), жирный шрифт и подчеркивание в цитатах всюду мои - А.Сь.

19 Об использовании глагола «иметь» в спряженной форме и инфинитива как одной из особенностей русского языка евреев см., напр.: С.М. Степанов, ор. cit., с. 434-436; И. Кабанен, Одесский язык: больше мифа или реальности?, «Slavica Helsingiensia» 2010, № 40, с. 289; A. Verschik, Jewish Russian and the Field of Ethnolect Study, «Language in Society» 2007, № 36, c. 225 .

20 Идишская транскрипция приводится по системе ИВО/ YIVO (Идишер Висншафтлэхэр Институт/ Institute for Jewish Research).

21 Здесь и далее произведения цитируются по изданию: I. Babel, Portret własny, tłum. J. Pomianowski, Bydgoszcz 1994. Страницы указываются в тексте статьи в круглых скобках с пометкой $K$ (Król), TO (Tak to robiono w Odessie), O(Ojciec), LK (Lubka Kozak), жирный шрифт и подчеркивание в цитатах всюду мои - А.Сь. 
ко слов, которые соответствуют по значению слову «грязь», понимаемому как «нечистота, неряшливость, неопрятность» ${ }^{22}$, но к наиболее часто употребляемым из них причисляется: во-первых, dos shmuts (средний род), во-вторых, der brud (мужской род), в третьих, dos/der koyt (средний или мужской род) $)^{23}$. Интересны при этом родовые колебания, т.е. одно и то же существительное может относиться к мужскому и женскому роду, к среднему и мужскому или к среднему и женскому ${ }^{24}$. Баська, героиня бабелевского рассказа, приписывает русскому существительному «грязь» род его идишского эквивалента, т.е., скорее всего, «der brud» или «dos/der koyt». Впрочем, возможно и другое объяснение. Обратим внимание, что овчины «прокисшые», а затем старые, ненужные; они «валяются по полу». Глагол «валяться» означает «лежать, будучи небрежно брошенным» ${ }^{25}$. Все это создает ощущение беспорядка, который героиня старается преодолеть, выбрасывая овчины за окно. Поэтому если принять, что под «грязью» имеется в виду «беспорядок», то на самом деле «грязь» - по мнению говорящей представляет собой родовую кальку с идишского der balagan ${ }^{26}$, существительного мужского рода. Тогда совершенно ясным становится «согласование» героиней рассказа по роду существительного «грязь» с пригагательным «невыносимый» и местоимением «этот». Польский переводчик решает данную проблему по другому. А именно путем применения существительного «brud» во множественном числе вместо более подходящего в анализируемом контексте единственного числа, что позволяет реципиенту перевода достаточно адекватно воспринять текст: «Wprost niemożliwość, jakie tu u tatunia brudy - powiedziała i wyrzuciła przez okno rozkisłe baranice walające się na podłodze - ale ja skończę z tymi brudami [...]» (O, c. 309-310).

Очередной пример: «Об чем думает такой папаша? Он думает об выпить хорошую стопку водки, об дать кому-нибудь по морде [...]» (KO, с. 19). С целью выявления в процитированном отрывке кальки идишского построения фразы, начнем сначала с указания в нем ошибок с точки зрения норм русского литературного языка. Так, во-первых, это применение предлога «об» вместо «о» перед словами с начальным согласным звуком ${ }^{27}$, во-вторых, опущение из главной части сложноподчиненного предложения предложно-местоименного сочетания «о том» (предлог «о» + указательное местоимение «это» в косвенном падеже) и, как следствие, редукция подчинительного союза «чтобы» в придаточной его части. Соответственно сказанному, правильный вариант анализируемого отрывка должен выглядеть так: «О чем думает такой папаша? Он думает о том, чтобы выпить хорошую стопку

22 Толковый словарь русского языка: 80000 слов и фразеологических выражений, ред. С.И. Ожегов, В.Ю. Шведова, 4-е изд., Москва 1997, с. 148.

23 «dirt» B: Comprehensive English-Yiddish Dictionary: (based on the lexical research of Mordkhe Schaechter), eds. G. Schaechter-Viswanath, P. Glasser, Bloomington-Indianapolis 2016, c. 193.

24 Э.М. Фалькович, ор. cit., с. 673.

25 Толковый словарь..., с. 68.

26 «mess》 в: Comprehensive English-Yiddish Dictionary..., с. 444.

27 См.: Трудности словоупотребления и варианты норм русского литературного языка, ред. К.С. Горбачевич, Ленинград 1973, с. 272. 
водки, о том, чтобы дать кому-нибудь по морде [...]». Отмеченное различие, вероятно, является интерференцией синтаксической системы и нормы идиша, согласно которой анализируемый нами фрагмент на языке евреев-ашкеназов может выгладеть так: «Vegn vos trakht der papashe? Er trakht vegn oysdrinkn a glezl, vegn shlogn emetsn [...]». Обратим внимание, что oysdrinkn может означать инфинитив или, как здесь, отглагольное существительное. Нарушение синтаксиса русского предложения объясняется тем, что инфинитив «выпить», от которого отглагольное существительное не образуется, употребляется именно в его функции наподобие идишского oysdrinkn. Отсюда и появляется «думает об выпить» как калька trakht vegn oysdrinkn. В польском варианте интересующий нас отрывок представляется следующим образом: «Względem czego może myśleć taki tatunio? On może myśleć względem wypić porządnego kielicha, względem dać komuś po mordzie [...]» (TO, с. 300). Переводчик, как видим, применяет похожее на оригинал строение предложения: за предлогом «względem» следует инфинитив. Это решение не является нормой польского языка («względem» сочетается не с инфинитивом, а с существительным или местоимением в дательном падеже), вследствие чего адекватность в переводе достигается.

Вернемся еще к цитированному выше фрагменту на русском языке, в котором обратим внимание на слово «папаша». Несмотря на уменьшительно-ласкательный суффикс «-аш-(а)» ${ }^{28}$, оно окрашено пренебрежением, явно просторечно и употребляется по отношению к пожилым мужчинам ${ }^{29}$. В подобном значении выступвет на идише слово papashe, но оно даже по форме диминутивом не является, поскольку в нем уменьшительный суффикс отсутствует. Впрочем, широко распространенные в идише уменьшительные формы личных имен употребляются для выражения положительного эмоционального отношения. Так, например, имя Moyshele, выступающее в исходном тексте как «Мойсейка» (КО, с. 25), а в польском варианте как «Mosiek» (TO, с. 307), может относится не только к мальчику, но и к взрослому мужчине ${ }^{30}$. Однако, учитывая анализируемый нами фрагмент и контекст Одесских рассказов в целом, слово «папаша», скорее всего, получает ироническо-пародийное переосмысление, подобно как и уменьшительные формы личных имен, например: «Беня», «Колька», «Савка», «Песя», «Маня». И имеено в таком же шутливом смысле удачно передается в польском варианте как ,tatunio», так и соответственно «Benia», «Kolka», «Sawka», «Pesia», «Мапіа» и другие. Впрочем, применение диминутивов - это для еврейского

28 «-аш-(а)» - формообразовательная единица, образующая имена существительные мужского и женского рода с ласкательным значением (мамаша, Маняша, Костяша, папаша и м.п.), в: Новый словарь русского языка. Толково-словообразовательный, ред. Т.Ф. Ефремова, т. I: А-О, Москва 2001, с. 55.

29 Современный русский язык. Социальная и функциональная дифференциация, ред. Л.П. Крысин, Москва 2003, с. 67.

30 См. R. Witkowski, Jidysz. Gramatyka praktyczna, Poznań 2015, c. 37. 
языка явление очень характерное ${ }^{31}$. Поэтому «чрезмерное» их присутствие в русскоязычном тексте можно считать интерференцией языка идиш.

Не менее интересные результаты дает рассмотрение следующего фрагмента: «-Кто будет здесь наконец за хозяина? [...] Я здесь буду за хозяина» $(K O$, с. 21$)$. Здесь наблюдается применение предложного управления глагола вместо беспредложного: «быть (за кого?) за хозяина» вместо «быть (кем?) хозяином», видимо, вследствие влияния соответствующей глагольной предложной конструкции на идише: $\boldsymbol{m a k h n}$ far emetsn ${ }^{32}$. Польский вариант применяется по синтаксической аналогии к исходному фрагменту, что позволяет реципиенту перевода уловить «картавость» речи героя произведения: «- No kto tu będzie w końcu za gospodarza? [...] Ja tu będę za gospodarza» (TO, с. 303).

Перед тем, как остановиться более подробно на правилах построения простого предложения на идише, присмотримся такой особенности речи евреев одесского цикла, как частое, казалось бы, избыточное, употребление личных местоимений. Приведем пример:

[...] - когда вы умрете, $\boldsymbol{я}$ похороню вас на первом еврейском кладбище, у самых ворот. Я поставлю вам, Эйхбаум, памятник из розового мрамора. Я сделаю вас старостой Бродской синагоги. Я брошу специальность, Эйхбаум, и поступлю в ваше дело компаньоном [...]. Я убью всех молочников, кроме вас [...]. Я выстрою вам дачу на шестнадцатой станции... $(K$, с. 15$)$

С одной стороны - учитывая точку зрения грамматической нормы русского языка - местоимение «я» это подлежащее единственно возможное в данном случае, поскольку никаким другим словом нельзя обозначить субъект действия, если глагол выступает в первом лице единственного числа. С другой стороны, есть тому и другое, более простое объяснение: калька из идиша. Тогда чрезмерная повторяемость личных местоимений объясняется интерференцией структуры идишского предложения, в котором подлежащее должно быть выражено то ли при помощи личного местоимения, то ли существительного ${ }^{33}$. Так, в языке идиш предложения, такие как, например, «Читаю газету», то есть без личного местоимения «я» невозможны, поскольку ikh leyen a tsaytung без $i k h$ воспринимается как повелительное наклонение («Читай газету») $)^{34}$. В польском переводе повтор местоимения, а затем и рифм высказывания героя сохранить вполне удается:

[...] - Kiedy pan umrze, to ja pana pochowam na pierwszym żydowskim cmentarzu, koło samej bramy. Ja panu postawię, Eichbaum, pomnik z różowego marmuru. Ja pana zrobię starostą Brodzkiej synagogi. Ja rzucę swój fach, panie Eichbaum, i przystąpię do

31 См., например: Э.М. Фалькович, ор. cit., с. 687; D. Katz, Grammar of the Yiddish language, London 1987, с. 63-69; Подробное описание уменьшительных форм на идише и способов их образования, см.: S. Neuberg, Yiddish [в:] Word-Formation. An International Handbook of the Languages of Europe, Vol. 4., ed. H.P. Müller, Berlin-Boston 2016, c. 2470-2472.

32 U. Weinreich, Modern English-Yiddish, Yiddish-English, New York 1977, c. 562.

33 D. Katz, op. cit., c. 224.

34 Похожий пример см.: Э.М. Фалькович, op. cit., с. 710. 
pańskiego interesu jako wspólnik [...]. Ja pozabijam wszystkich pachciarzy, prócz pana [...]. Postawię panu willę na szesnastej stacji... (K, c. 296)

Заметим, кстати, что в идише, подобно другим германския языкам, основной «покрой» синтаксиса следует по типу V2 (англ. Verb Second) схемы SVO (англ. Subject, Verb, Object) ${ }^{35}$. Иными словами, в порядке членов предложеня сказуемое всегда располагается на второй позиции, в то время как прямое дополнение и подлежащее могут менятся местами. Поэтому вполне правильными являются как предложение «Я знаю тетю Хану» (K, c. 14$)$ [«Ikh ken mume Khone»], так и «Тетю Хану знаю я» [«Mume Khone ken ikh»], причем, подчеркнем, подлежащее, так или иначе, в структуре идишского предложения - часть необходимая.

И, наконец, еще одна черта речи евреев Одесских рассказов, а именно сложное предложение, составные части которого связываются сочинительной связью, выраженной союзом «и..., и...» вследствие влияния характерной для языка идиш синтаксической структуры $\left(i \ldots i^{36}\right)$. Присмотримя к примеру:

Объясни мне, Мугинштейн, как другу: вот получает он от меня деловое письмо: отчего бы ему не сесть за пять копеек на трамвай $\boldsymbol{u}$ не подъехать ко мне на квартиру $\boldsymbol{u}$ не выпить с моей семьей стопку водки $\boldsymbol{u}$ закусить чем Бог послал? (KO, с. 22)

В польском переводе, как увидим ниже, достичь адекватности вполне удается:

Wytłumacz mi, Muginsztejn, jak przyjacielowi: zaczynam z facetem korespondencję handlową, to dlaczego nie miałby wsiąść do tramwaju za pięć kopiejek i wstąpić do mojego mieszkania, i wypić w moim rodzinnym gronie kieliszek wódki, i przegryźć czym Bóg dał? (TO, c. 303)

Подводя итоги, можно констатировать следующее: найболее «рельефные» примеры особенностей речи героев-евреев Одесских рассказов, как было показано, представляются на самом деле калькированием идишской структуры предложения. А варьирование родовых форм существительных и предложное/ беспредложное управление глагола, казалось бы, явление нетипичное - это последствие влияния флексии языка идиш. Что касается адекватности воспроизведения данных особенностей речи героев в польском переводе по отношению к принимающей его культуре, то это посложнее. В польском варианте рассказов отступления от языковой нормы, как было показано, в большинстве случаев сохраняются, однако они приобретают иной, чем в оригинале, характер. В принимающем текст культурном пространстве язык героев-евреев считается просто отстающим от нормы литературного польского языка, в то время как в исходной культуре - как раньше упоминалось - в зависимости от знаний реципиента, данные отступления воспринимаются то ли как, скажем, обычное «коверканье» русского языка,

35 H. den Besten, C. Moed-van Walraven, The Syntax of Verbs in Yiddish [в:] Verb Second Phenomena in Germanic Languages, eds. H. Haider, M. Prinzhorn, Berlin 2012, c. 111.

36 Ibid., c. 712. 
то ли как «коверканье», являющиеся интерференцией языка идиш. Иными словами, перевод анализированных нами фрагментов адекватен культурному пространству получателя с точки зрения воссоздания «некорректности» языка героев, но не коннотации, обусловленных еврейской культурой как таковой. В производном тексте данные коннотации вызваны не сколько калькированием структур языка идиш, столько употреблением диминутивов или слов, называющих еврейские десигнаты, связанные например с религией (Тора, раввин и т.п.). Итак, бабелевские герои-евреи в польской версии Одесских рассказов, словами одного из них, по-еврейски «говорят мало, но они говорят смачно».

\section{Литература}

Бабель И., Автобиография [в:] того же: Избранное, Москва 1966.

Бабель И., Король, Как это делалось в Одессе, Отеи, Любка Козак [в:] того же: Малое собрание сочинений, Санкт-Петербург 2014.

Вайнштейн М., А листья снова зеленеют: страницы еврейской русскоязычной литературы, Иерусалим 1988.

Вершик А., О русском языке евреев, «Die Weltder Slaven» 2003, vol. XLVIII.

Фалькович М., О языке идии [в:] Русско-еврейский (идиш) словарь, ред. М.А. Шапиро, И.Г. Спивак, М.Я. Шульман, Москва 1984..

История русской советской литературы в 4-х томах, т. 1 (1917-1929), ред. А.Г. Дементьев, Москва 1967.

Кабанен И., Одесский язык: больше мифа или реальности?, «Slavica Helsingiensia» 2010, № 40 .

Комиссаров В.Н., Современное переводоведение, Москва 2002.

Кузьменко П.В., Самыле скандальные треугольники русской истории, Москва-Владимир 2012.

Левин Ф., И. Бабель. Очерк творчества, Москва 1972.

Либерман Я.Л., Исаак Бабель глазами еврея, Екатеринбург 1996.

Новый словарь русского языка. Толково-словообразовательный, ред. Т.Ф. Ефремова, т. І: А-О, Москва 2001.

Огинский Р., Свобода смеяться [в:] Юмор начала XX века: Сборник, Москва 2003.

Плетнев Р., История русской литературы ХХ века, Энглвуд 1987.

Русская литература ХХ века (1917-1920-е годы), т. 1, ред. Н.Л. Лейдерман, Москва 20127.

Смирнов В., Крошка Чахес Бабель, Одесса 2010.

Смирнов В., Одесский язык, Одесса 2008.

Современный русский язык. Сочиальная и функцииональная дифференцииация, ред. Л.П. Крысин, Москва 2003.

Степанов С.М., Російське мовлення Одеси: монографія, Одесса 2004.

Толковый словарь русского языка: 80000 слов и фразеологических выражений, ред. С.И. Ожегов, В.Ю. Шведова, 4-е изд., Москва 1997. 
Трудности словоупотребления и варианты норм русского литературного языка, ред. К.С. Горбачевич, Ленинград 1973.

Babel I., Portret własny, tłum. J. Pomianowski, Bydgoszcz 1994.

Comprehensive English-Yiddish Dictionary: (based on the lexical research of Mordkhe Schaechter), eds. G. Schaechter-Viswanath, P. Glasser, Bloomington-Indianapolis 2016.

Den Besten H., Moed-van Walraven C., The Syntax of Verbs in Yiddish [в:] Verb Second Phenomena in Germanic Languages, eds. H. Haider, M. Prinzhorn, Berlin 2012.

Kabanen I., Johdatus Odessan. Kielen Erikoispiirteisiin (Введение в особенности одесского языка), Masters Dissertation, University of Helsinki 2008, https:// docplayer.ru/27486272-Johdatus-odessan-kielnen-erikoispiirteisiin-vvedenie-v-osobennosti-odesskogo-jazyka.html (доступ: 25.12.2018).

Katz D., Grammar of the Yiddish Language, London 1987.

Lewicki R., Obcość w odbiorze przekładu, Lublin 2000.

Neuberg S., Yiddish [в:] Word-Formation. An International Handbook of the Languages of Europe, vol. 4., ed. H.P. Müller, Berlin-Boston 2016.

Verschik A., Jewish Russian and the Field of Ethnolect Study, «Language in Society» 2007, № 36 .

Weinreich U., Modern English-Yiddish, Yiddish-English, New York 1977.

Witkowski R., Jidysz. Gramatyka praktyczna, Poznań 2015. 